\title{
Occult Hepatitis B: Case History
}

\author{
Olga Zamorshchikova ${ }^{1}$, Snezhana Sleptsova ${ }^{1,{ }^{*}}$, Keskilene Petrova $^{1}$, Maria Savvina ${ }^{1}$ \\ and Spiridon Sleptsov ${ }^{2}$
}

\author{
${ }^{1}$ North-Eastern Federal University, Medical Institute, Yakutsk, 677000, Russia \\ ${ }^{2}$ Yakutsk Scientific Center for Complex Medical Problems, Yakutsk, 677000, Russia \\ *Corresponding author. Email: ss.sleptsova@s-vfu.ru
}

\begin{abstract}
There is no HBsAg in the presence of HBV replication in patients with chronic viral hepatitis. This phenomenon was called occult hepatitis B. Russian researches referred as "hidden HBV infection". We conducted a clinical analysis of the medical history of patient I. with chronic HBV infection in the cirrhotic stage. The patient had suffered from liver disease for 10 years, which occurred latently and only last year manifested pains in the right upper quadrant abdominal pain, jaundice, skin itching, dyspeptic syndrome in the form of nausea, vomiting. The diagnosis of occult hepatitis B was diagnosed in 2020. Antibodies were found to nuclear (anti-HBc > 10.0) and surface (anti-HBs $331 \mathrm{mMe} / \mathrm{ml}$ ) antigens of $\mathrm{HBV}$ infection, with negative results on $\mathrm{HBsAg}$ and the absence of DNA-HBV in PCR during the examination. Morphological examination of biopsy lifetime liver material confirmed hepatitis $\mathrm{B}$ virus in liver tissue.
\end{abstract}

Keywords: chronic viral hepatitis, occult hepatitis B, hidden HBV infection

\section{INTRODUCTION}

Occult hepatitis B (OHB) is a special and complex form of HBV infection for clinical diagnosis, diagnosed throughout the world. The initial description was given in the late 70s last century [1]. However, the term "occult hepatitis $\mathrm{B}$ " and the concept of disease development were defined only in 2008 [2]. The absence of HBsAg in the serum, characteristic of OHB, leads to the patient's late appeal for specialized medical care. In most cases, the patient is hospitalized at the stage of the first decompensation of cirrhosis and at the same time learns about the disease. That is why it is considered rational to expand the panel of screening markers of hepatitis $B$ virus (HBV) to include $\mathrm{HBcAb}$. It has now been established that the presence of $\mathrm{HBcAb}$ cannot be only a marker of a previously acute $\mathrm{HBV}$ infection, but also a sign of a current chronic "occult" infection [2]. It is important to note that in occult hepatitis, antibodies to other markers of this virus may be absent. [3] The etiological affiliation of the disease to HBV infection in this category of patients can be confirmed morphologically (puncture liver biopsy or post-mortem examination). A number of clinical morphological studies indicate the identity of the pathological process in patients with chronic liver diseases, both with "isolated" $\mathrm{HBcAb}$ and in patients with serum HBsAg. It is the examination of liver tissue for HBV that makes it possible to confirm the cause of the disease. Nonspecific morphological changes in the liver are known, which were previously used as markers of viral hepatitis B: orcein-positive inclusions when colored by Shikota, "matte-vitreous" cells and cells with "sand nuclei." Major intra-nuclear inclusions and nuclear polymorphism now have the greatest diagnostic importance. Virus virions and their components can also be detected by electron microscopic examination of liver tissue. However, a direct morphological sign of chronic hepatitis $\mathrm{B}$ is undoubtedly the diagnosis of $\mathrm{HBsAg}$ and $\mathrm{HBcAg}$ in immunohistochemical analysis. The positive result in any of the above methods can be regarded as the presence of HBV infection. Currently, the "occult" HBV infection is intensively studied, many issues remain debatable [4-6]. There is an obvious need for new studies, primarily aimed at further studying the course of occult HBV infection in immunosuppression conditions, as well as the study of complications of the disease, such as acute liver failure in patients with cirrhosis and hepatocarcinoma. [7] 


\section{PURPOSE OF THE RESEARCH}

We presented a case history, diagnostic studies in occult chronic hepatitis B were analyzed with determination of clinical course features and structural changes in liver tissue.

\section{MATERIALS AND METHODS}

Clinical and pathomorphological examination of a patient with chronic hepatitis B with cirrhosis was carried out. In patient I., there was no blood in the serum $\mathrm{HBsAg}$ and antibodies to $\mathrm{HBcAg}$ and $\mathrm{HBsAg}$ were detected. Standard clinical-laboratory and instrumental research methods generally accepted in hepatology were carried out. The patient was determined serum hepatitis $\mathrm{B}$ markers by ELISA: HBsAg, HBsAg, HbcAg, HBeAg, HBeAg, DNA-HBV in blood plasma was detected by PCR (sensitivity 100 $\mathrm{IU} / \mathrm{ml}$. A puncture liver biopsy was performed (material with serial sections, stained with hematoxylin-eosin). The degree of histological changes was assessed by METAVIR scale, Knodell index.

\section{CASE-STUDY}

Patient I., 51 years old, was observed with a clinical diagnosis: Chronic hepatitis unspecified. Cirrhosis of the liver (class B by CP, 7 points.), fibrosis: F4 (> = $12.5 \mathrm{kPa}$ ). Portal hypertension. Varicose veins of the esophagus 2-3 stage. esophageal bleeding. Moderate post-hemorrhagic anemia. Secondary thrombocytopenia. Ascite.

Height $-174 \mathrm{~cm}$, weight $84 \mathrm{~kg}$, BMI: 27.74 . Complaints of bloating after eating. Well-being is satisfactory. Adequate, satisfactory condition. The skin is clean; the peripheral lymph nodes are not enlarged. The tongue is clean, wet. There are no wheezes. Rhythmic pulse, 62 beats per min. Heart tones clear, BP $122 / 79$ mm.pm. The boundaries of the heart are not expanded. The abdomen is painless, the liver is not enlarged, the spleen does not palpate. Low back shaking painlessly on both sides, there are no dysuric phenomena. There is no swelling, the stool is normal.

Epidemiological history: the patient was not ill with acute viral hepatitis. A close relative suffered from hepatitis B with recovery in the family. He denies alcohol abuse, according to the words he uses alcohol weekly.

There was a history of hyperbilirubinemia (without cutaneous itching) on the background of untested cytolytic syndrome. According to the description of MRI and abdominal RCT - the presence of moderate ascites with rapid positive dynamics on the background of pathogenetic treatment. According to the last abdominal ultrasound: signs of slightly expressed diffuse changes in the liver, initial splenomegaly. There are no signs of pronounced portal hypertension. There's no Ascite. Analyses from 30.09.2020: bilirubin $101 \mu \mathrm{mol} / 1-3$ points, INR -1 point, total protein normally -1 point, presumably ascite -1 point, encephalopathy -1 point, total -7 points by $\mathrm{CP}$ scale class B cirrhosis of the liver. Rapid positive dynamics in the level of bilirubin was noted on the background of the pathogenetic treatment.

For differential diagnosis, a puncture liver biopsy was performed. Sections of liver tissue were additionally prepared from the presented paraffin block, and immunohistochemical examination (HBsAg, $\mathrm{HBcAg}, \mathrm{CD} 138$ ) was performed. Histologically, a fragment of liver tissue with altered structure due to the formation of numerous broad vascularized porto-portal and porto-central septs forming fibrous tissue fields, wicking areas of liver parenchyma.

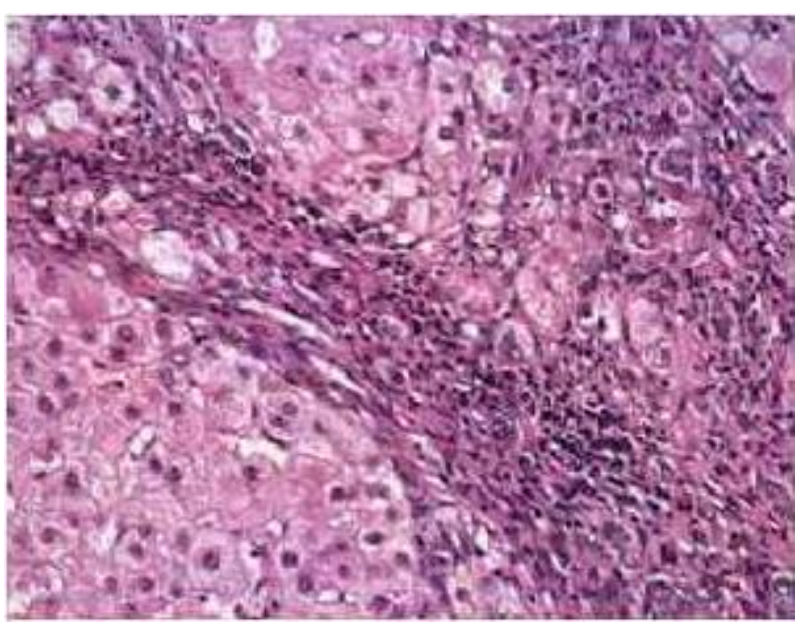

Figure 1. Chronic hepatitis with high histological activity (coloured. hematoxylin-eosin. X400)

The stroma of portal tracts is roughly sclerosed, unevenly infiltrated by lymphocytes with admixture of single polymorphonuclear leukocytes. Bile ducts are represented in all portal tracts, individual native ducts are expanded; the content of bile ducts is excessive due to sprawls of mainly small, located in coarse fibrous tissue, newly formed ducts with slit-like lumens mainly in peripheral sections of portal tracts. There is uneven common, often diffuse, lymphohistiocytic infiltration located among degeneratively altered hepatocytes or in the place of groups of dead hepatocytes in the periportal parts and inside the hepatic lobes. The plasmocellular nature of diffuse periportal infiltration is not expressed, CD138 + plasma cells in the composition of cell infiltrates were not detected. There is common, sharp degree of expression, proliferation of Coopffer cells. Unevenly expressed capillary cholestasis. Coarse fibrosis of hepatic vein walls and peripheral polymorphocellular infiltration. Hepatocytes are polymorphic, partly with enlarged hyperchromic nuclei, some of which contain small mat- 
oxyfilic intranuclear inclusions. The hepatocyte cytoplasm is grainy or unevenly lumped, lumpy, expanded. Single hepatocytes, less than $10 \%$, contain large fatty vacuoles in the cytoplasm. Part of hepatocytes, mainly centrolobular parts of hepatic lobes, have pronounced cholagenic pigmentation of cytoplasm. There are no signs of ductal cholestasis. $\mathrm{HBcAg}$ wasn't revealed in liver tissue by immunohistochemical test of HBsAg expression. Conclusion: Chronic hepatitis with high histological activity (IGA by Knodell = 13 points, by METAVIR A3) with pronounced fibrosis phenomena (degree of fibrosis by Knodell $=4$ points, by METAVIR F4) and manifestations of intrahepatic (capillary and intracellular) cholestasis. The specific nosological form of chronic diffuse liver disease (chronic hepatitis) was not established in patient I.

Needle liver biopsy, as glass with serial sections stained with hematoxylin-eosin. A column of liver tissue with impaired histoarchitectonics, anastomosing wide portal tracts, enveloping and crossing slices and pseudo-slices from a cluster of false bile passages, with weak loose lymphomonocytic infiltration, extending beyond the plate with admixture of single neutrophils. Bile duct epithelium proliferating. Fragments of liver veins with lumen narrowing, hyalinosis of the wall with single segmentonuclear leukocytes, expressed endothelial proliferation. There is a pronounced proliferation of Kupfer cells in the whole fragment. Frequent inflammatory infiltrates around dying hepatocytes, in sinusoids, scarce lymphocytic infiltration are inside the lobes. Hepatocytes are large with penile cytoplasm with moderate polychromasia of nuclei with oxyphilic inclusions. Intracellular and smallflow focal cholestasis. Fibrosis ++++ , inflammation + $+/+++$, inclusions + . Conclusion: Chronic viral hepatitis (morphologically type B) of moderate activity with anular sclerosis of liver tissue, cholestasis. According to METAVIR scale - A2, F4 (fig.1). Chronic hepatitis B is a global health affecting 3\% of the world population and causing $\sim 800,000$ deaths per year due to cirrhosis and hepatocarcinoma [7, 8]. Large-scale epidemiological studies have proved that the probability of transforming chronic hepatitis B into liver cirrhosis and hepatocarcinoma development correlates with the level of viral load in blood plasma.

Subsequently, patient I. was given a consultation at the federal center due to the previous diagnosis: Chronic hepatitis of unclear etiology with liver cirrhosis (F-4st.$38.5 \mathrm{kPa}$, class $\mathrm{B}$ by $\mathrm{CP}-7$ points). This diagnosis was established 4 months ago, when there was a sharp deterioration in health, jaundice of the skin, enlargement of the abdomen. The patient was hospitalized at the place of residence, where pronounced jaundice and ascites were revealed. Bilirubin reached $520 \mu \mathrm{mol} / 1$ due to direct fraction, cytolysis of more than 20 norms, the decrease in the prothromine index was up to $26 \%$. There was no itching of the skin. He received conservative treatment: hepatoprotectants, albumin, infusions of freshly frozen plasma, diuretics, but significant improvement occurred only after a course of plasmopheresis (No. 4) and hemosorption (No. 1).

When examined in dynamics: the patient's condition was stable. He improved significantly, he became more active, with good appetite. The skin was smug with a slight subicteric tint, the subictericity of the sclera was preserved. Single telangioectasias, palmar erythema was poorly expressed on the chest, a single expanded vein was determined in the abdomen. There were no swelling and pastosity. The heart and lungs were of normal ranges. The abdomen was soft, accessible by deep palpation, painless at all points, the fluid in the abdomen was not determined, the liver at the edge of the rib arch, the spleen at the edge of the rib arch $+1.0 \mathrm{~cm}$. The stool was stained, with a tendency to constipation, the urine was light. In laboratory analyses: minimal cytolysis (ALT 30.0, AST 51.8, U/L) and cholestasis phenomena (bilirubin - $34.47 \mu \mathrm{mol} / \mathrm{L}$, GGT $82 \mu \mathrm{U} / \mathrm{L}$ ) were preserved, protein-synthetic liver function improved. In the hemogram, white blood cells were $-6,89 \times 10 * 9 / 1$, red blood cells $-3,77 \times 10 * 12 / 1$, hemoglobin $112 \mathrm{~g} / \mathrm{l}$, platelets $327 \times 10 * 9 / 1$, formula without significant clinical deviations, ESR was $69 \mathrm{~mm} / \mathrm{h}$.

Clinical laboratory data from 25.01.21: General blood test developed: white blood cells $-7,93 * 10^{9} / 1$; red blood cells $-2.17 * 10^{12}$; hemoglobin $-59 \mathrm{~g} / \mathrm{l}$; HCT $18 \%$, MCV-82,9 fL, MCH - 27.3 pg, MCHC-329 g/l, platelets $-96.1 * 10^{9} \mathrm{~g}$ 'L (155-366), basophils $-0.8 \%$; eosinophils - $0.06 \%$; neutrophils segmentonuclear $79.7 \%$; lymphocytes - $13.1 \%$; monocytes - $6.2 \%$; $\mathrm{ESR}-55 \mathrm{~mm} / \mathrm{h}$.

Biochemical blood analysis: total protein $-59 \mathrm{~g} / \mathrm{l}$; bilirubin total - $44.1 \mu \mathrm{mol} / \mathrm{l}$; direct $19.1 \mu \mathrm{mol} / \mathrm{l}$; blood glucose - $8.1 \mathrm{mmol} / \mathrm{l}$; urea $-7.5 \mathrm{mmol} / \mathrm{l}$; blood creatinine - 88; blood amylase - $31 \mathrm{U} / \mathrm{l}$; ALT- $93 \mathrm{U} / \mathrm{l}$; AST- 239 U/l, INR - 1.98; PTI - 36.8 \%, APTT - 33.1.

Blood type and rhesus factor: blood type A (II), $\mathrm{Rh}$ positive.

ALT Serum is a marker of cytolysis, i.e., the degree of hepatocyte damage is characterized by the activity of this enzyme [9]. During histological examination in a patient with cirrhosis, hepatitis activity was assessed as high histological activity (IGA_Knodell) - 13 points.

According to the ultrasound of the abdominal organs, the liver was enlarged, the left lobe was $9.6 \mathrm{~cm}$, the right lobe was $16 \mathrm{~cm}$. The liver contours were tuberous, fuzzy, the angle of the liver was smoothed. The echostructure was heterogeneous, coarse-grained, in the right lobe, in all segments iso-echogenic "pseudonodes" were determined, merging with each other, with an approximate diameter of $2 \mathrm{~cm}$ to $5 \mathrm{~cm}$, the blood flow was not clearly determined by CDI. Echo density was increased. The intrahepatic bile ducts were not 
expanded. Portal vein was $1.5 \mathrm{~cm}$. The gallbladder was partially contracted. The shape was ovoid, dimensions $4 * 1.8 \mathrm{~cm}$, pure in the lumen. The total bile duct was $0.4 \mathrm{~cm}$. The pancreas was not enlarged, dimensions: head $2.5 \mathrm{~cm}$, body $1.6 \mathrm{~cm}$, tail $2.2 \mathrm{~cm}$. The contours were fuzzy, uneven. Echostructure was heterogeneous, echo density was unevenly reduced. Wirsung's duct was not expanded, no effusions were detected in the small gland. The spleen was moderately enlarged, the area was $49 \mathrm{~cm}^{2}$, the contours were even, clear, the echostructure was fine-grained. Echo density: average. The kidneys were typically located. Size: right kidney $11 * 5.6 * 5.8 \mathrm{~cm}$, parenchyma thickness $-2 \mathrm{~cm}$. The pyelocaliceal system was not expanded, compacted. Conclusion: Heptosplenomegaly. Echo signs of cirrhosis of the liver with portal hypertension. The transition to hepatocellular carcinoma was not ruled out. Diffuse changes in pancreatic parenchyma. Contracted gallbladder. Compacting the sinuses of both kidneys. Free fluid in the abdomen and pelvis.

A puncture biopsy confirmed the diagnosis of chronic hepatitis and liver cirrhosis, but the etiology of the disease was not established. At that time, hepatitis B and $\mathrm{C}$ markers in ELISA, as well as anti-mitochondrial antibodies, were negative. Antibodies to HBV were found Only in recent blood tests by ELISA: nuclear antigen (anti-HBc > 10.0) and surface antigen (anti-HBs $331 \mathrm{mMe} / \mathrm{ml}$ ), with negative results of $\mathrm{HBsAg}$ and DNA-HBV by PCR. This spectrum of markers can indicate the latent phase of hepatitis B - occult hepatitis B. It is important to emphasize HBsAg detection does not characterize the state of "carrier of the virus," but a chronic process with various degrees of activity.

The patient was assigned strict diet, no physical activity, no alcohol and conservative pathogenetic therapy. A clinical diagnosis has been established: Chronic hepatitis of unclear etiology. Occult hepatitis $\mathrm{B}$ ? Cirrhosis of the liver (class B by $\mathrm{CP}-7$ points). Treatment is currently ongoing.

Thus, HBsAg concentration in peripheral blood serum generally reflects the level of DNA-HBV accumulation in liver cells. High levels of DNA-HBV in patients with chronic HBV infection with different degrees of fibrosis severity, liver cirrhosis and, in contrast, a significantly lower ratio of infected to uninfected liver cells in patients with inactive $\mathrm{HBsAg}$ carrier, as well as with co-infections, including HBsAgnegative, were consistent with the work of colleagues, showing a low level of hepatitis B replication when coinfected with hepatitis $\mathrm{C}$ and hepatitis $\mathrm{D}$. The absence of serum HBsAg likely demonstrates a low concentration of HBV DNA in liver tissue. At the same time, according to the clinical recommendations of EASL (2012), the simultaneous detection of the above serological markers in the blood serum in the absence of HBV DNA makes it possible to diagnose the "HBsAg- negative" phase of HCV [10], and not to consider the infection complete.

\section{CONCLUSION}

Occult hepatitis B occurred in patient $\mathrm{I}$. in the progressive form of hepatitis with the development of the cirrhotic stage of the disease. The fact of the presence of viral hepatitis B markers in liver tissue and blood serum proves the viral etiology of the disease, as well as confirms the clinical diagnosis of chronic hepatitis B. A morphological examination of the liver in patient I. with occult chronic hepatitis B established moderate activity of the pathological process in the liver.

Our studies proved that serum $\mathrm{HBcAg}$ could serve as a surrogate marker of $\mathrm{HBV}$ infection, and the possibility of adverse outcomes of occult hepatitis B in the form of transformation into liver cirrhosis, and subsequently into hepatocellular cancer. According to studies carried out in Yakutia, patients examined after liver transplantation in most cases showed the total anti$\mathrm{HBc}$, which indicated the persistence of the virus in the organism. It is necessary to introduce donor blood and its components, as well as organ donors, the determination of not only HBsAg, but also total anti$\mathrm{HBc}$ in order to avoid infection of recipients into the examination system due to the high incidence of chronic forms of viral hepatitis B in the Republic of Sakha (Yakutia).

\section{REFERENCES}

[1] O.I. Raduto, Clinical and economic aspects of hepatitis with parenteral transmission, Epidem. \& infect. dis. Topical iss. 3 (2014).

[2] S.S. Sleptsova, Parenteral viral hepatitis and their outcomes in the Republic of Sakha (Yakutia), Monograph, North. Fed. Univ. M.K. Ammosova, 2017, 208 p.

[3] J. Blackberg, K. Kidd-Ljunggren, Occult hepatitis $B$ virus after acute self-limited infection persisting for 30 years without sequence variation, J. Hepatol. 33(6) (2000) 992-997.

[4] J.H. Hoofnagle, L.B. Seeff, Z.B. Bales, H.J. Zimmerman, Type B hepatitis after transfusion with blood containing antibody to hepatitis B core antigen, N. Engl. J. Med. 298 (1978) 1379-1383.

[5] G. Raimondo, J.P. Allain, M.R. Brunetto et al., Statements from the Taormina expert meeting on occult hepatitis B virus infection, J. Hepatol. 49 (2008) 652-657.

[6] J. Li, G.M. Zhao, L.M. Zhu et al, Liver pathological changes and clinical features of 
patients with chronic hepatitis B virus infection in their immune tolerant phase and non-active status, Chin. J. Hepatol. 15(05) (2007) 326-329.

[7] Z.L. Wang, W.P. Liu, G.Q. Wang, Relationship among pathological changes in liver tissues and level of serum ALT, virology of patients with chronic HBV, Chin. J. Hepatol. 5 (2008) 388-390.

[8] A. Schweitzer, J. Horn, R.T. Mikolajczyk et al., Estimations of worldwide prevalence of chronic hepatitis B virus infection: a systematic review of data published between 1965 and 2013, J. Lancet. 386, (2015) 1546-1555.

[9] EASL, Clinical Practice Guidelines on the management of hepatitis $B$ virus infection, $J$. Hepatol. 67 (2017) 370-398.

[10] EASL, Clinical Practice Guidelines: Management of chronic hepatitis B virus infection, J. Hepatol. 57 (2012) 167-185. 